\title{
Nos limites da humanidade: necropolítica, direitos humanos e ilegibilidade estatal no Brasil
}

In the Limits of Humanity: Necropolitics, Human Rights and the Illegibility of the State in Brazil

Dans les limites de l'humanité : nécropolitique, droits humains et illisibilité de l'État au Brésil

Tiago Lemões

\section{(2) OpenEdition}

\section{Journals}

Edição electrónica

URL: http://journals.openedition.org/rccs/10948

DOI: $10.4000 /$ rccs. 10948

ISSN: 2182-7435

\section{Editora}

Centro de Estudos Sociais da Universidade de Coimbra

\section{Edição impressa}

Data de publição: 1 dezembro 2020

Paginação: 27-46

ISSN: 0254-1106

\section{Refêrencia eletrónica}

Tiago Lemões, « Nos limites da humanidade: necropolítica, direitos humanos e ilegibilidade estatal no Brasil », Revista Crítica de Ciências Sociais [Online], 123 | 2020, posto online no dia 15 dezembro 2020, consultado o 17 dezembro 2020. URL : http://journals.openedition.org/rccs/10948 ; DOI : https:// doi.org/10.4000/rccs. 10948 


\title{
TIAGO LEMÕES
}

\section{Nos limites da humanidade: necropolítica, direitos humanos e ilegibilidade estatal no Brasil*}

\begin{abstract}
Neste texto analiso os mecanismos pelos quais agentes estatais mobilizam regimes de verdade e retóricas de direitos humanos para racionalizar e, ao mesmo tempo, ocultar rastros de brutalidade deixados por diferentes formas de violência estatal. Para explicitar e discutir estes mecanismos, descrevo uma experiência etnográfica envolvendo instituições jurídicas, universitárias e movimentos sociais em torno da investigação da morte de uma pessoa em situação de rua, em Porto Alegre, no contexto da Copa do Mundo FIFA 2014 no Brasil. Com isso, busco situar, em meio ao poder necropolítico, as ferramentas discursivas e institucionais que permitem ao Estado negar-se como perpetuador do terror frente a uma ampla campanha pela garantia dos direitos humanos das pessoas em situação de rua.
\end{abstract}

Palavras-chave: Brasil; direitos humanos; intervenção do Estado; necropolítica; violência policial.

\section{Introdução}

A razão ocidental é, não raro, assustadora e fascinante, não apenas pelas velhas promessas de verdade, saber, progresso e desenvolvimento, mas principalmente por suas expostas intimidades com o que há de mais brutal e mortífero nas periferias do capitalismo: o aniquilamento racionalizado de vidas humanas. A quem é subserviente a produção da razão e da verdade? Quais são as peles que ela salva, as vozes que ela silencia e os corpos que ela consome? O que muda em nossas convicções quando os discursos humanitários que ela mobiliza também impulsionam e camuflam as mais violentas e desumanas intervenções em regiões historicamente devastadas pela dominação colonial e imperialista?

Tomando estas indagações como pano de fundo reflexivo, a minha intenção, neste artigo, é analisar os mecanismos pelos quais agentes estatais

\footnotetext{
* Algumas seções deste artigo têm por base a minha tese de doutorado (Lemões, 2017a).
} 
mobilizam regimes de verdade e retóricas de direitos humanos para racionalizar e, ao mesmo tempo, ocultar rastros de brutalidade deixados por diferentes formas de violência. Para explicitar e discutir estes mecanismos do ponto de vista empírico, lançarei mão de uma experiência etnográfica envolvendo instituições jurídicas, universitárias e movimentos sociais em torno da investigação da morte de uma pessoa em situação de rua, em Porto Alegre, capital do Rio Grande do Sul, no contexto da Copa do Mundo FIFA 2014 no Brasil. Neste intento, busco situar, em meio às artimanhas do poder necropolítico, as ferramentas discursivas e institucionais que permitem ao Estado negar-se como perpetuador do terror frente a uma ampla campanha pela garantia dos direitos humanos.

\section{Regimes violentos de intervenção}

Atualmente, quem mais tem incidido sobre a centralidade do conceito de razão para a crítica política contemporânea é o pensador camaronês Achille Mbembe (2016 [2003]). Para ele, a razão figura como elemento chave ao projeto de modernidade e ao sentido hegemônico de soberania sustentado por teorias normativas da democracia, que definem a política como projeto de autonomia consensual e coletiva a ser alcançado por homens e mulheres livres. Mas frente aos imaginários de liberdade, igualdade e autonomia que sustentam as noções hegemônicas de soberania, qual o lugar das experiências de racionalização da morte? Tal indagação também está no centro das preocupações de Mbembe, para quem a luta pela autonomia está longe de operar como projeto primordial das formas de soberania, muito mais empenhadas na instrumentalização da existência humana e no aniquilamento de corpos e populações. Essa leitura, definitivamente avessa às heranças da filosofia moderna, toma a vida e a morte como categorias fundadoras da soberania, com expressão máxima no direito de matar, no apelo constante à exceção e à construção ficcional do inimigo (ibidem).

Essa discussão aponta para uma relativa insuficiência analítica da noção foucaultiana de biopolítica, segundo a qual a coextensividade entre o direito soberano de matar e o cultivo e proteção da vida inscreve-se no funcionamento dos Estados modernos, para os quais o aniquilamento de vidas se faz em função da potência e segurança de outras existências. Em contraposição, Mbembe defende que a matança dispensa alegações quanto à potencialização da vida e da espécie humana, expressando uma configuração específica do poder soberano: a necropolítica. Teríamos, nesta noção, a tradução de novas experiências de submissão de populações à destruição máxima e a novas tecnologias de aniquilação que não visam a inscrição de corpos em aparatos disciplinares, mas na sua total apreensão na ordem econômica 
do massacre, nos limites de uma topografia marcada por intervenções que preservam traços comuns de Estados escravistas.

Mas a potência da noção de necropolítica, como bem infere Mbembe, expressa a sua amplitude analítica ao abarcar práticas mortíferas cujos efeitos não se expressam necessariamente na morte física, mas na produção de zonas de exposição de determinadas populações à morte ou a processos extremados de vulnerabilização. Trata-se de um fenômeno também abordado por Judith Butler (2017), para quem a vida política contemporânea não abarca determinados sujeitos, pois, apesar de uma generalizada pressuposição multicultural de comunidades estabelecidas, o que está em jogo são sujeitos vivos sem reconhecimento de suas vidas ou, nas palavras de Mbembe (2016: 146), sujeitos inseridos em "condições de vida que lhes conferem o status de 'mortos-vivos'”. Tais zonas adquirem maior visibilidade ao se considerar a dinâmica de poder moderno-ocidental, marcada pelo que Boaventura de Sousa Santos (2007) denomina de linha abissal, expressa pela tensão entre regulação/emancipação (presente em sociedades metropolitanas europeias) e apropriação/violência (materializada na produção de sub-humanidade pela destruição física, material e cultural).

Não é a primeira vez que estas perspectivas teóricas influenciam reflexões sobre as configurações históricas e políticas que enquadram populações-alvo do poder estatal. De minha parte, tenho insistido, há algum tempo, que a população em situação de rua, no Brasil, insere-se em um amplo contingente de vidas historicamente expulsas do projeto humanista, inferiorizadas, capturadas, condenadas ao extermínio indiferente ou à indiferença própria dos que os promoveram como selvagens e perigosos (Lemões, 2017a, 2017b). Paradoxalmente, tamanha indiferença não implica desinteresse em relação à intervenção da maquinaria estatal, sempre desejosa em conhecer, classificar, esconder e enclausurar presenças indesejáveis nos espaços públicos urbanos - pelo menos desde o final do século XIX. Assim, podemos afirmar, com segurança, que o braço repressivo e penal do Estado sempre esteve muito visível na história de determinados corpos, disseminando por todos os lados os seus traços biopolíticos, disciplinares e necropolíticos.

No entanto, se no Brasil um violento regime de intervenção estatal sobre vidas, corpos e condutas vem sendo registrado por vasta historiografia sobre o tema (Azevedo, 1987; Kowarick, 1987; Filho, 1995; Chalhoub, 2001; Diniz, 2004; Bernardo, 2010; Lara, 2012; Lima, 2014), muito ainda precisa ser dito sobre os modos discursivos e institucionais pelos quais o Estado silencia e oculta a sua comunhão com regimes contemporâneos de terror, ao mesmo tempo em que declara compromissos com a garantia de direitos humanos universais. Chego, aqui, ao objetivo central deste texto: analisar os 
mecanismos através dos quais agentes estatais mobilizam regimes de verdade para inferiorizar e responsabilizar supostas vítimas de suas ações, racionalizando e, ao mesmo tempo, ocultando insinuações de brutalidade, dor e sofrimento provocados por diferentes formas de violência estatal. Para explicitar e discutir estes mecanismos, descrevo uma experiência de engajamento etnográfico envolvendo instituições jurídicas, universitárias e movimentos sociais em torno da investigação do suposto assassinato de uma pessoa em situação de rua, em Porto Alegre, nas semanas que antecederam a Copa do Mundo FIFA 2014 no Brasil.

Tal contexto empírico foi explorado de diferentes formas por um conjunto de pesquisadores. A expansão da rede de interlocução estatal em defesa dos direitos humanos em Porto Alegre e o aumento de relatos sobre a violência contra a população de rua, no contexto da Copa do Mundo, foram questões analisadas por Leite (2016). Do mesmo modo, Fernandes (2015) explorou a dinâmica de denúncias em relação ao caráter violento e inquisitorial das práticas policiais, assinalando a formação discursiva e estratégica da politização das pessoas em situação de rua, inseridas em um campo de tensões que espelham relações de poder, divergência e resistência entre agentes públicos e militantes em situação de rua. Por sua vez, Schuch (2015) sugeriu que o caráter performativo dos direitos, dinamizado por militantes do Movimento Nacional da População de Rua (MNPR), por meio de escrachos, denúncias e rumores, teve o poder de expor certas barreiras dos referenciais dos direitos humanos, escancarando - pelo deslocamento entre fatos e rumores - os limites do fato jurídico individualizado e restrito à produção de provas concretas sobre a violência policial. ${ }^{1}$

Olhando para o mesmo contexto etnográfico, desenvolvi análises sobre a produtividade política da mobilização de pessoas em situação de rua

\footnotetext{
${ }^{1}$ Os envolvimentos e engajamentos etnográficos nos circuitos de mobilização junto à população em situação de rua na cidade de Porto Alegre foi possível, fundamentalmente, a partir de vínculos com projetos específicos de pesquisa e extensão, orientados por Patrice Schuch, no âmbito do Núcleo de Antropologia e Cidadania da Universidade Federal do Rio Grande do Sul (NACi/UFRGS). De 2013 a 2015, o projeto "Direitos humanos, moralidades e subjetividades nos circuitos de atenção à população em situação de rua" reuniu pesquisadores e estudantes de graduação e pós-graduação da UFRGS neste campo de investigação e mobilização social. Helena Lancelotti produziu sua pesquisa de mestrado e eu a minha pesquisa de doutorado. Na graduação, investigações e intervenções foram realizadas por Bruno Guilhermano Fernandes e Caroline Sarmento, estudantes de ciências sociais, além de Gabriela Jacobsen (2014) e Pedro Ferreira Leite (2016), cientistas sociais. Agradeço imensamente a colaboração de todos e todas, pelo compartilhamento de experiências e aprendizados, resultantes da dedicação ao trabalho antropológico em coletivos articulados. Além disso, agradeço principalmente a atenção e a confiança dos integrantes do jornal Boca de Rua e do Movimento Nacional da População de Rua, que sempre foram interessados e receptivos aos engajamentos etnográficos de pesquisadores, gerando uma colaboração fundamental e inspiradora para as reflexões elaboradas neste artigo.
} 
contra práticas e relatos de violência policial, remoções compulsórias e enclausuramentos forçados durante a Copa do Mundo. Especificamente, concentrei minhas reflexões sobre a atuação da Patrulha dos Direitos Humanos (PDH) - um coletivo formado por agentes do Ministério Público (MP), da Defensoria Pública da União (DPU), da Ouvidoria de Segurança Pública (OSP), por pesquisadores da Universidade Federal do Rio Grande do Sul (UFRGS), por integrantes da Comissão de Direitos Humanos da Câmara dos Vereadores de Porto Alegre (CEDECONDH) e por apoiadores e militantes do MNPR. Acompanhando a atuação da PDH no trabalho de coleta de denúncias de violência policial entre pessoas em situação de rua em diversos pontos da cidade, evidenciei a articulação entre garantia discursiva de direitos, autoprodução do Estado (sensível, comprometido e engajado) e a gestão de territórios ${ }^{2}$ e populações indesejáveis no espaço público (Lemões, 2017a).

Se a PDH teve visibilidade na mídia regional - o que permitiu a seus integrantes publicizar que, a despeito de relatos dispersos dos movimentos sociais, não existiam provas de higienização social na cidade - o surgimento de informações sobre um suposto assassinato desencadeou uma série de interações que, por um motivo evidente, permaneceu longe dos holofotes: a brutalidade das cenas descritas enterravam definitivamente qualquer afirmação positiva da $\mathrm{PDH}$ a respeito das práticas policiais em Porto Alegre. Por isso, neste artigo, dedico-me a descrever o meu envolvimento, junto aos militantes do MNPR e aos integrantes da PDH, nas investigações sobre o suposto assassinato de um homem em situação de rua, refletindo sobre os mecanismos estatais mobilizados para descartar a culpabilidade dos agentes da segurança pública na reprodução do terror, controle de informações e transfiguração de narrativas de violência em falsidades e intrigas.

Deste modo, busco situar, em meio ao poder necropolítico, as ferramentas discursivas e institucionais que permitem ao Estado negar-se como perpetuador do terror e afirmar-se como promotor dos direitos humanos,

\footnotetext{
${ }^{2}$ Especificamente nos estudos das áreas de geografia e ciências sociais, são muitas as definições e discussões sobre a noção de território. O que, no entanto, se apresenta como consenso na literatura atual é a crítica a uma abordagem enciclopédica e cartesiana que essencializa aspectos físicos e geográficos da conformação territorial (de Certeau, 2002; Haesbaert, 2007; Santos, 2008; Saquet, 2010). De minha parte, vinculo-me às inferências de Rogério Haesbaert (2007) e Marcos Saquet (2010) para valorizar a amplitude da concepção de território, que, na acepção destes autores, envolve poder, controle, dominação e apropriação do espaço físico e social, referindo-se, também, a mediações simbólicas que abarcam desigualdades de classe, gênero, raça e religiosidade, arquitetadas na historicidade e na dinâmica socioespacial. Tais referências são fundamentais à compreensão dos modos pelos quais o Estado, através de seu braço penal e repressivo (Wacquant, 2003), exerce a gestão de populações "indesejadas" em determinados territórios urbanos, mesmo quando atua declaradamente em nome da garantia dos direitos fundamentais.
} 
realizando um movimento inverso de inferiorização e responsabilização de outros sujeitos envolvidos nas narrativas sobre o assassinato. Valendo-se destes mecanismos, o Estado produz a sua própria ilegibilidade ao reiterar ausências documentais ou negar o acesso a informações que poderiam implicar os seus próprios agentes da segurança pública como suspeitos de um suposto crime. Assim, veremos que, através de seus "segredos e enigmas" (Bachtold, 2016), o Estado joga com as inúmeras possibilidades que lhe permitem ser constantemente reconstruído e, ao mesmo tempo, legitimado através de suas práticas, documentos e palavras (Das e Poole, 2004).

\section{Nos limites da humanidade}

"Cláudio Fonseca, 39 anos, negro, morador de rua, foi espancado por cinco policiais na madrugada do dia 23 de junho de 2014, no interior do Parque da Redenção, no centro da cidade. O corpo aguarda documentação no IML [Instituto Médico Legal] para identificação". Transmitida por uma integrante do Comitê Popular da Copa, ${ }^{3}$ a descrição acima foi repassada por e-mail aos participantes da PDH em 25 de junho por intermédio de Pedro, à época acadêmico do curso de ciências sociais da UFRGS e apoiador do MNPR. O título do correio eletrônico era alarmante: "Denúncia urgente: pessoa em situação de rua assassinada". Os requintes de crueldade descritos na mensagem contrastavam com as declarações midiáticas, publicadas quatro dias antes, que negavam qualquer ação de higienização social na cidade.

Em poucos dias, uma reunião na câmara dos vereadores foi marcada e contou com a presença de representantes da DPU, da OSP, da UFRGS, de centros de referência em direitos humanos da capital e região metropolitana, de vereadores e de militantes vinculados ao MNPR. O início das discussões foi marcado pela sobreposição de informações sobre o "caso Cláudio" e pela indignação com o que seria para Adriana, militante em situação de rua, a manifestação clara da violência de Estado. Curiosamente, os dados sobre a morte vieram de diversos lados como possibilidades a serem investigadas, embora tivessem sido supostamente confirmadas por um advogado vinculado ao Movimento Negro da cidade, que teria conversado pessoalmente com uma testemunha do crime. Os militantes do MNPR estavam visivelmente indignados com a notícia - diria que Adriana estava consternada - e cobravam atitudes imediatas, enquanto uma psicóloga vinculada à CEDECONDH produzia indagações que de alguma forma racionalizavam a

\footnotetext{
${ }^{3}$ Coletivo formado por várias organizações e movimentos sociais para fortalecer a luta contra processos de violação de direitos, deflagrados por projetos urbanos, ocasionados pela realização de megaeventos no Brasil.
} 
emoção manifesta ante a brutalidade daquele relato e explicitavam as imensas dificuldades em construir verdades sobre os relatos que chegavam por e-mail.

Um primeiro eixo de informações, cujas fontes eram incertas mas que as autoridades ali presentes já possuíam, foi sistematizado pela psicóloga: a família de Cláudio apenas manifestava o desejo de ter acesso ao corpo, sem a intenção de qualquer denúncia; uma pessoa teria testemunhado as agressões da janela de um apartamento e acionado o atendimento via ambulância; antes disso, outra pessoa (ou a própria testemunha) teria retirado do bolso de Cláudio um boleto de energia elétrica no qual constava o endereço de seus familiares, o que permitiu que fossem localizados e informados sobre o ocorrido. Por fim, a psicóloga apontou o desencontro de informações sobre a data em que Cláudio teria sido hospitalizado: supostamente ele teria agonizado de 16 a 23 de junho, quando fora internado no Hospital de Pronto Socorro (HPS). Essa possibilidade foi contestada por mim e por outro pesquisador, quando sugerimos ser impossível alguém permanecer uma semana com "crânio afundado, olhos perfurados e costelas quebradas" até receber atendimento médico.

Uma promotora pública ficou encarregada de solicitar à Secretaria de Segurança Pública (SSP) o acesso às câmeras de monitoramento (que jamais foram obtidas), enquanto a psicóloga ponderou não ser de nossa alçada investigar o caso. Em meio a tantos detalhes recheados de incerteza, nos faltava a materialidade do homicídio, o que impossibilitava qualquer iniciativa para publicizar o caso. Ao mesmo tempo em que não nos cabia investigar, também não poderíamos denunciar a situação, nos registros formais da burocracia estatal, sem a aquisição de "dados concretos" que permitissem ultrapassar narrativas sem provas materiais. Faríamos, assim, uma investigação por conta própria, reunindo todas as informações possíveis, dividindo tarefas e estudando o ocorrido a partir de seus problemas e possibilidades de resolução.

Embora estivéssemos partindo do pressuposto de que a morte teria sido provocada pelas agressões cometidas por cinco policiais, a maioria das indagações conduzia-nos à investigação sobre a existência de Cláudio e sobre a veracidade do acontecimento. Isso porque, pelos procedimentos administrativos, era impossível que qualquer policial fosse interrogado pelos agentes da OSP, encarregados tão somente de encaminhar denúncias à Corregedoria Geral, órgão responsável pela apuração de responsabilidades criminais da polícia militar. A investigação de denúncias não é atribuição da OSP, mas como seus agentes estavam engajados em um contexto de amplo debate, alimentado por rumores e casos concretos de violência policial, houve um esforço daquele órgão em buscar elementos que fundamentassem a abertura de um expediente junto à Corregedoria. Por isso, os documentos 
de Cláudio precisavam ser encontrados, assim como o corpo, as testemunhas e os familiares. Disso dependia o acesso a informações que jamais foram obtidas, como a identificação dos policiais em plantão e as filmagens das câmeras de vigilância pública.

Conforme a promotora envolvida, para solicitar acesso às câmeras de vigilância, era imprescindível saber exatamente o local e o horário do ocorrido. A partir desta informação, me dirigi a um agente da OSP para saber de que forma poderíamos contatar a testemunha e identificar o local exato das agressões. Para ele, no entanto, o foco das investigações deveria ser a irmã e a mãe de Cláudio - as quais, já sabíamos, não queriam falar sobre o caso. Em uma sexta-feira, a reunião entre os diferentes agentes envolvidos na questão foi finalizada com a divisão de algumas "tarefas investigativas" e indicação de outra reunião na semana seguinte, quando deveríamos ter reunido o máximo de informações possíveis que ajudassem na composição de uma denúncia fundamentada em alguma materialidade.

Durante o final de semana, concentrei esforços na interlocução com o Instituto Médico Legal (IML). Por telefone, apresentei-me como pesquisador à atendente do Instituto Geral de Perícias (IGP) e solicitei detalhes sobre o registro de entrada de corpos em casos de pessoas sem documentos de identidade. A funcionária explicou que em tais circunstâncias uma busca é realizada no sistema a fim de verificar o registro das impressões digitais e que, na ausência destes, somente os familiares podem fazer o reconhecimento fotográfico. Perguntei, então, se ela poderia verificar se nos registros de entrada de corpos constava o nome de Cláudio Luis Santos Fonseca, com entrada no dia 23 de junho. Prontamente a atendente esclareceu que naquele dia ela estava de plantão e nenhum corpo sem identificação ou com o nome de Cláudio teria dado entrada no IML. Quase como um desabafo, pensando alto, respondi: "mas onde está esse corpo, então!?”. Em resposta, antes de encerrar a ligação, a atendente arrematou: "ele pode estar internado no hospital".

Naquele final de semana eu praticamente não dormi, tomado pela ansiedade de resolução daquele quebra-cabeça que me atormentava pela descrição das circunstâncias da morte. Era impossível não imaginar a cena. Eu me perguntava como seria concebível tamanha incidência de ódio e frieza em uma ação permeada por requintes de crueldade. Certamente, muitos militantes envolvidos na investigação sentiram e pensaram o mesmo. $\mathrm{Na}$ semana seguinte, lembro de ter conversado com Adriana, militante em situação de rua, horas antes de uma reunião do MNPR, e percebi a transformação em seu corpo, roupas, fala e expressões faciais: estava visivelmente triste, introspectiva e com as roupas sujas - algo incomum em seu caso. 
Em um breve diálogo, ela disse estar deprimida com a história de Cláudio, sentindo-se impotente frente a tanta violência e impunidade.

O fato é que, cada qual a sua maneira, todos nós sentíamos um pouco dessa tristeza e impotência que, paradoxalmente, nos movia, dia e noite, em busca de "provas concretas", solicitadas pelos parceiros institucionais e por nossa própria sede de justiça. A brutalidade contida na descrição do crime envolvia-nos em uma complicada confusão moral, com a qual tínhamos que lidar, a um só tempo: o desafio em representar violações corporais tão extremas que pareciam marcar os limites da vida e da humanidade (Das, 1999) e o imperativo de comprovar estes atos - corríamos atrás do que justamente nos causava dor, raiva e medo.

\section{No deserto documental}

Ainda naquele final de semana, quando contatei o IGP, passei a integrar um grupo de apoiadores e militantes do MNPR. A intenção do grupo era conversar com algumas pessoas que habitavam o entorno do Parque da Redenção, com o objetivo de coletar qualquer informação relevante sobre o suposto assassinato. Por mensagens de celular, conversei com outros militantes e apoiadores do MNPR e marcamos um encontro às 19 horas, em um ponto do parque próximo à área de distribuição de comida realizada por um grupo religioso. Eu, no entanto, cheguei ao local sozinho, uma hora mais cedo. No ápice do inverno daquele final de junho, já era noite, o frio era intenso e a neblina limitava o alcance da visão, junto com a escassa iluminação pública da Avenida José Bonifácio, no limite leste do parque. Adentrei o local na expectativa de encontrar alguém para conversar sobre Cláudio. O primeiro rapaz a quem resolvi perguntar sobre o assunto, visivelmente incomodado com o questionamento, afirmou não ter sequer ouvido falar sobre o caso. $\mathrm{Na}$ chuva, em meio à penumbra, com os traços faciais escondidos sob o capuz do moletom, nervoso, inquieto e olhando para todos os lados enquanto falava comigo, aquele jovem - que, depois eu saberia, integrava um grupo de garotos de programa atuantes no local - sinalizava claramente que a minha presença naquele espaço, com perguntas de teor investigativo sobre crime e polícia, era indesejada e poderia trazer problemas para mim e/ou para ele. Naquele instante eu entendi o recado, me dei por conta do que estava fazendo ao ultrapassar o limite entre as narrativas sobre um crime violento, ocorrido em determinado lugar, e a composição viva desse mesmo lugar, marcado por outras ilegalidades, conectando-me com outros sujeitos que, direta ou indiretamente, povoam o Parque da Redenção com usos, negociações e moralidades múltiplas. Questionar sobre os envolvidos em um crime naquele espaço era como inquirir sobre toda uma rede de relações a qual eu 
sequer tive o cuidado de atentar ou conhecer previamente. Tal experiência foi o suficiente para refletir sobre a obstinação com a qual eu estava conduzindo as coisas, atropelando o mundo e querendo encontrar a todo custo, e até por conta própria, as provas que pudessem incriminar os perpetradores de um crime cruel, marcado por uma violência insuportável e inadmissível.

A neblina virou chuva e tive de acelerar passos ao longo da Avenida José Bonifácio, até chegar à parte mais iluminada do parque, nas proximidades com a Avenida Osvaldo Aranha. Ali encontrei o restante do grupo, já conversando com algumas pessoas que pareciam frustradas, pois, pelo clima chuvoso, a doação alimentar não aconteceria. Preocupados com o jantar, muitos haviam se deslocado de outros pontos da cidade, estavam com as roupas molhadas, com frio e, talvez por isso, não muito inclinados a conversar, já organizando seus pertences rumo a outros locais. Dois homens, no entanto, permaneceram conosco. Trabalhavam como guardadores de carro nas proximidades do HPS, a uma quadra do parque, e já sabiam sobre a morte de Cláudio. Sentados no encosto de um banco público, circundados por militantes e apoiadores do MNPR, eles foram enfáticos na menção de inúmeros casos de violência policial que se multiplicavam no interior do parque, destacando que a escuridão e a imensidão do local contribuíam para que os policiais fizessem o que bem entendiam com as pessoas em situação de rua.

Um deles, no entanto, assegurou ter conhecido Cláudio e o descreveu como um homem magro, de baixa estatura, negro e muito ágil, que costumava guardar carros nas redondezas do parque e do HPS. Por mais que solicitássemos outros detalhes, aquele homem apenas acrescentou que Cláudio era uma boa pessoa e que desapareceu misteriosamente. Esse desaparecimento, continuou o homem, coincidiria com um episódio no qual um guardador de carros teria sido baleado pela Polícia Militar (PM) na entrada de uma garagem próxima ao HPS e, em seguida, levado ao hospital. Embora também trabalhasse no local, o nosso segundo interlocutor, que relatou episódios violentos da polícia, nada disse sobre Cláudio. Terminamos a noite empolgados, por um lado, pois alguém parecia ter conhecido Cláudio e não estávamos atrás de um fantasma, mas frustrados, por outro: nenhuma dessas informações serviria, aos olhos do Estado, para comprovar um assassinato.

$\mathrm{Na}$ segunda-feira pela manhã, dia 30 de junho, recebi ligação de uma militante do MNPR e advogada integrante do Serviço de Assessoria Jurídica Universitária (SAJU/UFRGS), que tinha estado no IML, onde foi informada que a liberação de um corpo só poderia ser efetuada pela família biológica. Mas a informação que tínhamos - mesmo sem conhecer as fontes - era de que Cláudio constava como filho adotivo. A militante já sabia da inexistência de registro sobre o corpo entre os dias 16 e 24 de junho. 
Durante a conversa, compartilhamos a sensação angustiante frente a esse vazio documental de Cláudio, como se estivéssemos falando de alguém que nunca existiu e envolvidos em uma paranoia coletiva. No mesmo dia, soubemos que uma reunião havia sido marcada para o dia seguinte, entre o MNPR e um representante da Secretaria Nacional de Direitos Humanos (SNDH), em passagem por Porto Alegre, de quem seria cobrada uma posição mais efetiva na criação de uma política centrada no combate à violência contra pessoas em situação de rua. Seria, também, uma oportunidade para compartilhar a teia de incertezas na qual estávamos enredados naquela semana e, de alguma forma, pleitear soluções para o impasse.

$\mathrm{Na}$ terça-feira, às 9 horas da manhã, o representante da SNDH não compareceu, alegando que ninguém havia confirmado o compromisso com ele e que, portanto, voltaria para Brasília. Ainda assim, a reunião ocorreu com a presença de militantes do MNPR, apoiadores da rede socioassistencial, pesquisadores e estudantes da UFRGS. Na ocasião, relatamos o contato com o IML e as informações desconcertantes obtidas até o momento. Quando eu ainda levantava a possibilidade de verificarmos com mais atenção nos hospitais da cidade, considerando o relato sobre um homem baleado pela PM nas proximidades do Parque da Redenção, inesperadamente apareceram dois agentes da OSP que haviam participado de reuniões anteriores. Contra nossos inúmeros pontos de interrogação, aqueles agentes trouxeram em mãos um ponto final: para eles, o "caso Cláudio" estava encerrado e, por isso, se faziam presentes naquela reunião, esclarecidos que estavam pelas palavras de uma jovem cozinheira de escola pública: a irmã de Cláudio.

Convencida pela diretora da escola a conversar com os agentes, a irmã teria revelado que uma pessoa havia retirado uma conta de energia elétrica do bolso de Cláudio e, seguindo o endereço, avisado os familiares. Ela também confirmou que seu irmão fora internado numa Unidade de Tratamento Intensivo no dia 16 de junho, falecendo sete dias depois, acrescentando que ela e a mãe teriam visitado Cláudio por repetidas vezes durante a internação. Revelou ainda que o irmão era natural de Cruz Alta, região centro-norte do estado do Rio Grande do Sul, e que o único documento que possuía era a certidão de nascimento. Imediatamente após a conversa, os agentes consultaram o registro de visitas de hospitais públicos e não encontraram o nome dos familiares que teriam visitado Cláudio, assim como não havia dados sobre internação em nome do mesmo. Por fim, os agentes teriam consultado o cartório do município de Cruz Alta, descobrindo, igualmente, a inexistência de qualquer registro. Para eles, estava claro que, por alguma razão, a irmã inventara a morte do irmão. 
Frente a essa conclusão, um militante manifestou sua desconfiança com o encerramento do caso, pois para ele as explicações ainda eram muito duvidosas. Partilhando a mesma insatisfação, perguntei se a polícia não teria condições de apagar todos os registros de Cláudio durante a internação. Para os agentes da OSP, no entanto, isso seria praticamente impossível. Para a militante do SAJU/UFRGS, também era impossível que "uma mulher, branca, de classe alta, tenha metido a mão no bolso de um morador de rua, negro, e subido o morro para encontrar a família”. Outro pesquisador, por sua vez, fez um alerta: deveríamos tomar muito cuidado ao falar do caso, pois correríamos o risco de prejudicar as testemunhas, as pessoas que transmitiram inicialmente as informações e a própria família de Cláudio. Outra apoiadora do MNPR e técnica da rede assistencial, assegurou que a irmã de Cláudio, por ter "inventado aquela história", poderia até ser "processada pelo Estado", ao que outras pessoas advertiram: "não vamos dar ideias para que o Ministério Público prejudique pessoas inocentes”.

\section{Silêncios, desertos e armadilhas}

Por mais visível, por mais presente que estivesse nas palavras e nas dores, por mais que pudesse ser verbalizada inúmeras vezes, a violência não existia para o Estado que estava ali, nas suas margens, mas que, assim mesmo, mantinha seus enigmas, suas portas muito bem fechadas. Bem sabemos que o encontro do Estado com suas margens é tanto mais profícuo quanto maior é a sua materialização em corpos, carimbos, cartões, formulários e documentos oficiais (Bachtold, 2016). Sem matéria e evidência, a verdade da existência é deslocada ao reino das invenções monstruosas. Como elucida Peirano (2009) sem esses objetos poderosos que são os documentos, com vida e dinâmica próprias, é impossível comprovar que somos quem afirmamos ser. Eles são meios de identificação, de controle e, quando potencializados por políticas de segurança pública, fornecem vias para a iluminação de certas zonas sombrias da criminalidade (ibidem).

Ao mesmo tempo, documentos podem abrir caminhos para a ilegalidade ou ilegibilidade de certas práticas, quando são duplicados, falsificados, eliminados, ou quando possuem forças assimétricas, como nos casos em que um auto de resistência é mais poderoso que um exame cadavérico. Uma verdadeira guerra documental se instaura. Debruçado sobre os fenômenos de desaparecimento forçado no Rio de Janeiro, Araújo (2016) constata que

\footnotetext{
${ }^{4}$ No Brasil, os autos de resistência, enquanto um dispositivo jurídico do Código de Processo Penal, são registros que permitem aos agentes da segurança pública justificarem os homicídios que cometem quando estão em serviço. Por conta dos autos de resistência, ao menos na sociedade brasileira, os casos de homicídio cometido por policiais raramente são investigados.
} 
quando as denúncias apontam para a participação de policiais ou ex-policiais em homicídios, seja em colaboração ou em disputa com as milícias do tráfico, a grande barreira erigida é o corporativismo policial. Nesse processo, a facilidade com a qual se registram autos de resistência ressalta a recorrência de uma classificação administrativa pela qual a investigação das mortes é dispensada. Mas enquanto o auto de resistência, como documento, produz legalidade para os autores da morte, encerrando qualquer investigação - mesmo quando exames cadavéricos apresentam fortes indícios de execução -, o desaparecimento dissolve as materialidades do homicídio e os "segredos do Estado" criam barreiras praticamente intransponíveis. O resultado é que a dimensão do terror se inscreve em "corpos virtuais" que podem ter sido torturados e esquartejados, mas cuja corporalidade é desmaterializada a ponto de seus rastros serem refeitos unicamente por suposições (Araújo, 2016).

Enquanto Araújo (ibidem) explora a relação íntima entre corpos e crimes, as reflexões possíveis a partir do "caso Cláudio" também instauram a interdependência de documentos, corpos e crimes. A conclusão de que tudo não passara de uma invenção da irmã por motivo banal não exclui o fato de que a morte, se não é inventada, é construída por uma série de percursos institucionais e agenciamentos coletivos. Como explica De Lucca (2016), o encontro do Estado com o corpo é o primeiro passo nessa "invenção da morte". Em seguida, agentes autorizados devem analisar e confirmar o falecimento, apontar o horário, o local, a causa da morte e transformar, legalmente, o corpo em cadáver. Além dessa codificação mortuária, é necessário construir um saber sobre a vida interrompida: nome, origem, parentela, documentação pessoal. Uma vez que nenhum familiar reconheça o corpo, a vala comum ou as instituições de pesquisas biomédicas são os principais destinos dos que terminam a vida nas ruas.

Em parte, isso explica a busca incessante pelos registros documentais de Cláudio, uma vez que o primeiro passo para a "invenção da morte" não fora dado: o encontro com o corpo. Ou seja, o percurso para a construção de um cadáver estava desfalcado, sem a principal materialidade que lhe confere sentido e, por isso, documentos que atestassem sua passagem pelo mundo institucional eram tão valiosos. No entanto, as narrativas sobre o caso mexeram com outras questões que ultrapassam os problemas meramente relacionados à burocracia da morte. Não estávamos falando de uma morte qualquer - ainda que, se tratando de pessoas em situação de rua, sabemos que o que se manifesta como problema público são as suas vidas e não as suas mortes (De Lucca, 2016). Não tínhamos um corpo, mas tínhamos agentes estatais sendo apontados como algozes de um ato brutal, cuja descrição 
parecia tornar insignificante a inexistência real ou virtual de materialidade. Sabíamos que identificar ou mesmo assumir publicamente os rumores sobre um corpo com "crânio afundado, costelas quebradas e olhos perfurados", decorrente de uma ação policial, traria sérios problemas aos órgãos públicos em um contexto de debate midiático sobre a violência contra pessoas em situação de rua. Definitivamente, não era qualquer morte.

Ao longo da caçada aos registros de Cláudio, vimos que nenhum órgão público obteve ou cedeu qualquer informação. No IML, nos hospitais e nos cartórios, Cláudio não existia. Graças à barreira dos procedimentos burocráticos - guardiã de segredos estatais que evitam liberação e publicização de dados (Araújo, 2016) -, as câmeras de vigilância não foram acessadas e os policiais que trabalhavam no $9 .^{\circ}$ Batalhão no momento do suposto ocorrido não foram identificados nem interrogados - justamente porque nenhuma denúncia pôde ser encaminhada à Ouvidoria, ante a carência de detalhes sobre as circunstâncias e características do fato. No meio de um deserto documental, foi dado veredicto à inexistência de uma vida. Vida e morte potencialmente inventadas por familiares, por instituições, por dispositivos de gestão.

Nessa luta por versões e invenções, um desequilíbrio de forças transmutou vítima em algoz, colocando familiares sob suspeita de uma invenção realizada ao avesso das criações legais e legítimas do poder estatal. A força de tal legitimidade inventiva foi sentida na constatação de que era melhor, por bem ou por mal, encerrarmos o assunto. Não porque as provas inexistiam, mas pelo fato de estarmos produzindo outras provas contra os familiares interrogados, que poderiam ser "processados pelo Estado". É justamente essa inversão súbita na correlação de forças que surpreende e atormenta a apreensão dos desfechos arrematados pela maquinaria estatal. Em outro contexto empírico, buscando entender o processo pelo qual acontecimentos marcados por crimes brutais contra meninos em Altamira (Pará) potencializaram causas políticas envolvendo familiares e agentes estatais, Lacerda (2015) mostrou com detalhes o modo como as perguntas formuladas na investigação revelavam quem poderia ser incriminado. Os delegados preocupavam-se menos com o possível envolvimento dos acusados do que com a condição financeira das famílias envolvidas, a rotina dos pais e a relação com os filhos - o que para os familiares das vítimas representava uma intromissão ofensiva em suas vidas, assim como um desinteresse e omissão da parte dos órgãos responsáveis.

No "caso Cláudio", localizar, procurar, questionar, interrogar e averiguar foram verbos que ganharam vida numa relação muito específica entre Estado e família, quando, malgrado suas intenções humanitárias, os agentes da OSP 
localizaram na periferia uma jovem negra a ser interrogada na presença de sua superior, a diretora da escola onde trabalhara. Em uma simples conversa, de acordo com os agentes, as perguntas incidiram sobre a composição familiar, a vida laboral da moça, a relação com o irmão no período em que esteve hospitalizado e as possibilidades de encontrar registros institucionais de Cláudio. Como resultado, o caso foi encerrado pela afirmativa de que a família inventara a morte por algum motivo. $\mathrm{O}$ vazio documental foi o que legitimou esse desfecho no qual a família aparece como autora de um engano, pois as instituições estatais, na percepção dos agentes da OSP, não teriam a pretensão ou o poder desaparecedor (Araújo, 2016) para eliminar os rastros de uma pessoa.

Outras pesquisas etnográficas apontam para fenômenos semelhantes. Nos casos analisados por Lacerda (2015), era recorrente a adoção de mecanismos policiais de inferiorização, desmoralização e responsabilização da família pela violência cometida contra seus filhos. Ainda em Araújo (2016), encontramos a relação entre inferioridade de casos de desaparecimento e inferioridade atribuída à favela e seus habitantes, reforçada na proliferação de discursos oficiais nos quais o consumo e o tráfico de drogas parecem justificar os desaparecimentos e desresponsabilizar os órgãos incumbidos de solucioná-los. Evidenciando a construção do desaparecimento de pessoas como um problema social no Brasil, Ferreira (2013) também demonstrou que, registrado nas delegacias como um fato de menor importância, o desaparecimento é compreendido pelos policiais como um problema de família, pelos gestores públicos como um problema de famílias desestruturadas e pelos familiares como um problema de polícia e de Estado.

Há, portanto, um jogo desigual de forças em torno da "verdade" sobre a violência e a personificação de seus perpetradores. Casos semelhantes ao de Cláudio descambam para a subalternidade atribuída e justificada por uma territorialidade inferior, cravejada de estigmas, desconfianças e ilegalidades que vinculam o desaparecimento aos "desvios" de uma família monoparental, "desestruturada" (ibidem) e negligente no cuidado e criação dos filhos (Lacerda, 2015). Por mais de uma vez ouvimos que Cláudio era adotado. As figuras femininas da mãe e da irmã estiveram o tempo todo em evidência, sem nenhuma referência masculina, tributária do difuso modelo de família nuclear, deixando vazios que foram preenchidos pela atribuição muda de falhas, ausências e invenções sombrias sem motivos evidentes. A arapuca estava armada: o caso, uma vez encerrado por ter sido considerado uma invenção - o que impedia outras invenções -, silenciava a publicização de contestações mais enérgicas. Era como se, caso continuássemos com aquela história, outras pessoas seriam prejudicadas. Sem corpo, sem documentos, sem crime. 


\section{Reflexões finais}

$\mathrm{Na}$ relação com o Estado, a realidade da vida e da morte se produz via documentos oficiais. Destruí-los é um modo eficiente de desmoronar uma certa realidade, de apagar determinadas intervenções brutais e corroer existências indesejáveis. Não por acaso, durante a Copa do Mundo FIFA 2014, em Porto Alegre, enquanto nenhuma documentação sobre Cláudio foi encontrada, outros relatos de violência praticada pela polícia traziam a informação de que os agentes da segurança pública estavam absolutamente engajados na destruição de carteiras de identidade das pessoas em situação de rua. Mesmo assim, os parceiros institucionais que se aproximaram do MNPR estimulavam as pessoas a confeccionar seus documentos, na intenção de evitar ou minimizar prisões ou abordagens violentas.

Ao que parece, ninguém prestou atenção no fato de que a destruição de documentos de identificação dos que vivem nas ruas era um modo de minar o reconhecimento oficial de suas existências e dificultar o acesso aos parcos direitos conquistados. Com isso, é possível endossar assertivas que aproximam Estado e bruxaria (Borges, 2012) e concebem documentos como amuletos protetores (Peirano, 2009). Para Borges (2012), assim como a bruxaria, o Estado existe como ficção abstrata e conjuntural (por meio das definições de burocracia, violência, direitos, governo, território e fronteira), mas também como entidade visível na medida em que seus efeitos interventivos são sentidos e dinamizados na realidade. Nessa perspectiva, documentos e estatísticas, que produzem controle burocrático e administrativo, possuem estatuto de realidade semelhante a qualquer outro oráculo (ibidem). Em um processo no qual o "sistema" é consultado a fim de cadastrar, verificar, identificar, confirmar ou solucionar injustiças (Bachtold, 2016), os "amuletos documentais" podem proteger algumas pessoas contra os males lançados pelos próprios enigmas do funcionamento estatal (Peirano, 2009). Ao mesmo tempo, os enigmas, ao limitarem a realidade social à documentação, nutrem-se de uma confusão muito útil ao Estado. Sem comprovações oficiais, relatos de um assassinato legitimaram as instituições estatais, que descartaram a culpabilidade de suas ações na reprodução do terror - efeito causado pelo controle de informações e pela relegação das experiências ao mundo dos relatos sem comprovação, comumente transfigurados em falsidades e intrigas pelo controle estatal sobre narrativas de medo e indignação (Trajano-Filho, 1993).

No entanto, é válido reconhecer que engajamentos e responsabilizações foram cobrados o tempo todo. Nessa dinâmica, enquanto o Estado produzia sua ilegibilidade ao interpretar, classificar fenômenos e fazer circular informações oficiais (Araújo, 2016), os militantes do MNPR reiteravam 
constantemente a continuidade de um regime marcado pela violência policial e pelas múltiplas formas de agressão no interior dos serviços de acolhimento institucional. Por isso, considero que as experiências etnográficas vivenciadas durante a Copa do Mundo iluminaram um debate sobre poder, violência e territorialidade que expõe experiências históricas e confronta sua obsolescência, reiterada nos discursos oficiais. Tais experiências funcionariam como "pílulas narrativas" que reproduzem a história (Trajano-Filho, 1993), lançam luz sobre uma territorialidade excludente e comunicam processos que criam vazios espaciais e morais, ancorados na retórica do novo que força deslocamentos, produz enclausuramentos e legitima o extermínio de corpos negros e periféricos - atualizando o que vem ocorrendo no espaço urbano desde que o fim do regime escravocrata anunciou que brancos e negros libertos dividiriam a mesma calçada. Impossível negar que o que se apresenta aos nossos olhos integra um regime necropolítico que faz da força violenta contra o outro uma política organizada nas dimensões sincrônicas e diacrônicas da experiência social, sem deixar de manipular a retórica dos direitos humanos a seu favor, no intuito de camuflar a brutalidade de suas intervenções, tão bem conhecidas na terra brasilis.

Revisto por Ana Sofia Veloso

\section{Referências bibliográficas}

Araújo, Fábio (2016), "Não tem corpo, não tem crime: notas sociológicas sobre o ato de fazer desaparecer corpos”, Horizontes Antropológicos, 22(46), 37-64.

Azevedo, Celia Maria (1987), Onda negra, medo branco. O negro no imaginário das elites do século XIX. Rio de Janeiro: Paz e Terra.

Bachtold, Isabele (2016), "Quando o Estado encontra suas margens: considerações etnográficas sobre um mutirão de estratégias de busca ativa no Estado do Pará”, Horizontes Antropológicos, 22(46), 273-301.

Bernardo, Kátia (2010), "Envelhecer em Salvador: uma página da história (1850-1900)". Tese de Doutorado em História Social, Universidade Federal da Bahia, Salvador, Brasil.

Borges, Antonádia (2012), “Ser embruxado. Notas epistemológicas sobre razão e poder na antropologia”, Civitas, 12(3), 469-488.

Butler, Judith (2017), Quadros de guerra. Rio de Janeiro: Civilização Brasileira. Tradução de Sérgio Lamarão e Arnaldo Marques da Cunha.

Chalhoub, Sidney (2001), Trabalho, lar e botequim. Rio de Janeiro: Editora Unicamp.

Das, Veena (1999), "Fronteiras, violência e o trabalho do tempo: alguns temas wittgensteinianos”, Revista Brasileira de Ciências Sociais, 14(40), 31-42. 
Das, Veena; Poole, Deborah (2004) "State and Its Margins", in Veena Das; Deborah Poole (orgs.), Anthropology in the Margins of the State. Santa Fe: School of American Research Press, 3-33.

de Certeau, Michel (2002), A invenção do cotidiano, vol. 2. Petrópolis: Vozes.

De Lucca, Daniel (2016), "Morte e vida nas ruas de São Paulo: a biopolítica vista do centro", in Taniele Rui; Mariana Martinez; Gabriel Feltran (orgs.), Novas faces da vida nas ruas. São Carlos: Edufscar, 23-44.

Diniz, Ariosvaldo (2004), A maldição do trabalho. João Pessoa: Manufatura.

Ferreira, Letícia (2013), "De problema de família à problema social: notas etnográficas sobre o desaparecimento de pessoas no Brasil contemporâneo”, Anuário Antropológico, 38(1), 191-216.

Fernandes, Bruno (2015), “'A gente vai continuar se escondendo da sociedade?’ - Notas etnográficas sobre a situação de rua, a violência e a discriminação em espaços urbanos”, Ponto Urbe, 16, 1-11. Consultado a 20.11.2019, em https://journals.openedition. org/pontourbe/2766.

Filho, Walter (1995), Mendigos, moleques e vadios na Babia do século XIX. São Paulo/ /Salvador: Hucitec/UFBA.

Haesbaert, Rogério (2007), O mito da desterritorialização: do "fim dos territórios" à multiterritorialidade. Rio de Janeiro: Bertrand Brasil [3. a ed.].

Jacobsen, Gabriela (2014), “Os peregrinos: uma etnografia itinerante de tempos-espaço e lutas em Porto Alegre”. Monografia de graduação em Ciências Sociais, Universidade Federal do Rio Grande do Sul, Porto Alegre, Brasil.

Kowarick, Lúcio (1987), Trabalho e vadiagem. A origem do trabalho livre no Brasil. São Paulo: Brasiliense.

Lacerda, Paula (2015), Meninos de Altamira: violência, luta política e administração pública. Rio de Janeiro: Garamond.

Lara, Silvia (2012), "No jogo das cores: liberdade e racialização das relações sociais na América Portuguesa setecentista”, in Regina Xavier (org.), Escravidão e liberdade. Temas, problemas e perspectivas em análise. São Paulo: Alameda, 69-93.

Leite, Pedro (2016), "Na luta com os peregrinos. Uma etnografia experimental com a população em situação de rua de Porto Alegre”. Monografia de graduação em Ciências Sociais, Universidade Federal do Rio Grande do Sul, Porto Alegre, Brasil.

Lemões, Tiago (2017a), "De vidas infames à máquina de guerra: etnografia de uma luta por direitos". Tese de Doutorado em Antropologia Social, Programa de Pós-graduação em Antropologia Social, Universidade Federal de Rio Grande do Sul, Porto Alegre, Brasil.

Lemões, Tiago (2017b), "O lado brutal da modernidade: a produção histórica da 'mendicância' como argumento para a violência estatal no Brasil”, Cadernos de Ciências Sociais da UFRPE, II(11), 126-161. 
Lima, Marcos (2014), “A vadiagem e os vadios: controle social e repressão em São Luís (1870-1888)”. Dissertação de Mestrado em História Social, Universidade Federal do Maranhão, São Luís, Brasil.

Mbembe, Achille (2016), "Necropolítica”, Revista Arte e Ensaios, 32, 123-152. Tradução de Renata Santini [orig. 2003].

Peirano, Marisa (2009), "O paradoxo dos documentos de identidade: relatos de uma experiência nos Estados Unidos”, Horizontes Antropológicos, 15(32), 53-80.

Santos, Boaventura de Sousa (2007), "Para além do pensamento abissal: das linhas globais a uma ecologia de saberes”, Novos Estudos, 79, 71-94.

Santos, Milton (2008), A natureza do espaço: técnica e tempo, razão e emoção. São Paulo: EDUSP [4. ${ }^{\mathbf{a}}$ ed.].

Saquet, Marcos Aurélio (2010), Abordagens e concepções de território. São Paulo: Expressão Popular [2. ${ }^{\mathrm{a}}$ ed.].

Schuch, Patrice (2015), “A produção performativa dos direitos”, Mesa 3, V Reunião de Antropologia da Ciência e da Tecnologia, maio de 2015, Universidade Federal do Rio Grande do Sul, Porto Alegre, Brasil. Youtube, 1 de julho de 2015. Consultado a 15.12.2019, em https://www.youtube.com/watch?v=C6fpB9-_nI8.

Trajano-Filho, Vilson (1993), Rumores: uma narrativa da nação. Série Antropologia. Brasília: Universidade de Brasília.

Wacquant, Loïc (2003), Punir os pobres: a nova gestão da miséria nos Estados Unidos. Rio de Janeiro: Revan. Tradução de Eliana Aguiar.

Artigo recebido a 11.03.2019

Aprovado para publicação a 22.07.2020

\section{Tiago Lemões}

Programa de Pós-Graduação em Política Social e Direitos Humanos, Universidade Católica de Pelotas Rua Gonçalves Chaves, n. ${ }^{\circ}$ 373, CEP: 96015-560, Pelotas, Rio Grande do Sul, Brasil Contacto: tiagolemoes@gmail.com ORCID: https://orcid.org/0000-0002-3538-3414

In the Limits of Humanity: Necropolitics, Human Rights and the Illegibility of the State in Brazil

In this paper, I analyze the mechanisms by which the agents of the state mobilize the rhetoric of human rights to hide the dif-
Dans les limites de l'humanité : nécropolitique, droits humains et illisibilité de l'État au Brésil

Dans cet article j'analyse les mécanismes par lesquels les agents de l'État mobilisent des régimes de vérité et des rhétoriques 
ferent forms of state violence. To explain and discuss these mechanisms, I describe an ethnographic experience involving legal institutions, universities and social movements around the investigation of the death of a homeless man, in the city of Porto Alegre, in the context of the 2014 FIFA World Cup in Brazil. In the context of the necropolitics of power, I explain the discursive and institutional strategies that allow the State to hide its violent interventions in the face of a broad campaign to guarantee human rights for the homeless. Keywords: Brazil; human rights; necropolitics; police violence; State intervention. des droits humains pour rationaliser et, par la même, masquer des traces de brutalité laissées par différentes formes de violence d'État. Pour expliquer et discuter ces mécanismes, je décris une expérience ethnographique impliquant des institutions juridiques et universitaires et des mouvements sociaux autour de l'investigation sur la mort d'une personne sans domicile fixe, à Porto Alegre, dans le cadre de la Coupe du Monde de la FIFA 2014 au Brésil. Je cherche ainsi à situer, dans le contexte du pouvoir nécropolitique, les outils discursifs et institutionnels qui permettent à l'État de cacher la terreur de ses interventions durant une vaste campagne visant à garantir les droits fondamentaux des personnes sans domicile fixe.

Mots-clés: Brésil; droits humains; intervention de l'État; nécropolitique; violence policière. 